\title{
Plasma Free Norepinephrine and Epinephrine Concentrations Following Diazepam-Ketamine Induction in Patients Undergoing Cardiac Surgery
}

\author{
S. M. Kumar, S. P. Kothary and E. K. Zsigmond \\ Department of Anesthesiology, University of Michigan Medical Center, \\ Ann Arbor, Michigan, U.S.A.
}

\begin{abstract}
Ketamine causes cardiovascular stimulation, presumably, by increasing central sympathetic activity. This study was undertaken to find out if diazepam in appropriate doses could abolish or moderate the central sympathetic and cardiovascular stimulation following ketamine in patients undergoing cardiac surgery.

Twelve patients, scheduled for valvular replacement (8) and direct aortocoronary bypass graft operations (4) were studied. After premedication with diazepam $0.15 \mathrm{mg} / \mathrm{kg}$ orally and morphine sulphate $0.15 \mathrm{mg} / \mathrm{kg} \mathrm{i} . \mathrm{m}$., they were induced with diazepam $0.3 \mathrm{mg} / \mathrm{kg}$ i.v., followed $10 \mathrm{~min}$ later by ketamine $2 \mathrm{mg} / \mathrm{kg}$ i.v. Direct arterial pressure by a strain gauge from the radial artery and heart rate by EKG were continuously recorded. Plasma free norepinephrine, measured by Vendsalu's method, in the arterial blood was $0.39 \pm 0.03 \mathrm{ng} / \mathrm{ml}$ prior to induction, $0.39 \pm 0.03 \mathrm{ng} / \mathrm{ml} 10 \mathrm{~min}$ after diazepam and $0.42 \pm 0.05 \mathrm{ng} / \mathrm{ml}(P>0.05) 5 \mathrm{~min}$ after ketamine administration. Plasma free epinephrine concentrations were $0.10 \pm 0.04 \mathrm{ng} / \mathrm{ml}$ prior to induction, $0.06 \pm 0.03 \mathrm{ng} / \mathrm{ml}(P>0.05) 10 \mathrm{~min}$ after diazepam and $0.01 \pm 0.003 \mathrm{ng} / \mathrm{ml}(P<0.05) 5 \mathrm{~min}$ after ketamine. Heart rate and systolic pressure did not change significantly throughout the study period. Diastolic pressures were elevated significantly $(P<0.05) 5 \mathrm{~min}$ after ketamine administration, amounting to a $12 \%$ increase over baseline.

Diazepam-ketamine induction in cardiac surgical patients did not result in clinically significant central sympathetic or cardiovascular stimulation.
\end{abstract}

Received 31 January, accepted for publication 10 May 1978

Ketamine has been recommended for anesthesia in patients undergoing open-heart surgery (CoRssen et al. 1970) and the critically ill (Chasapakis et al. 1973) because of its cardiovascular stimulant effects, resulting in increased heart rate, arterial blood pressure and cardiac output (VIRTUE et al. 1967, Tweed et al. 1972). The mechanism of the cardiovascular stimulation following ketamine could be a direct effect of the drug on the heart and/or peripheral vasculature or it could be due to indirect action through alterations in the autonomic outflow.

Direct myocardial stimulation by ketamine is unlikely because in dog heart-lung preparations it acts as a myocardial depressant
(Traber et al. 1968). Furthermore, ketamine, when given in increasing doses $(5-20 \mathrm{mg} / \mathrm{kg}$ ) to dogs with a complete epidural block, causes progressive myocardial depression, hypotension and no change in heart rate (Traber \& Wilson 1969). This suggests that its cardiovascular effects in normal animals are probably due to central sympathetic stimulation. Further evidence to support the contention that ketamine produces central sympathetic stimulation is provided by the studies of Zsigmond et al. (1974a) and IVANKovich et al. (1974). Zsigmond et al. showed a significant increase in heart rate, arterial blood pressure and plasma free norepinephrine concentration following the ad- 
ministration of ketamine in patients without cardiac disease, and Ivankovich et al. elicited circulatory stimulation by injecting ketamine directly into the vessels of the isolated cerebral hemispheres of goats in fractions of the doses used to elicit a similar response when it is injected into a peripheral vein.

Cardiovascular stimulation following induction of anesthesia with ketamine alone is also accompanied by increased myocardial work and myocardial oxygen consumption. Hence, use of this technique in patients with ischemic heart disease may be inadvisable, and its use in patients with any cardiac disease requires great caution (TwEed et al. 1972).

Several drugs have been shown either to moderate or to abolish the cardiovascular stimulation observed following ketamine; these include: hexamethonium (Traber et al. 1970a), atropine (Traber et al. 1970b), phentolamine (Traber et al. 1971), pentobarbital (Ivankovich et al. 1974), halothane (Stranley 1973), droperidol (Dundee et al. 1971) and diazepam (Zsigmond et al. 1974b).

We used diazepam prior to induction of anesthesia with ketamine for several reasons. In low doses $(0.1 \mathrm{mg} / \mathrm{kg}$ i.v. $)$ diazepam does not cause a significant change in heart rate, systemic arterial pressure, cardiac output or right ventricular dp/dt (DALEN et al. 1969, IKRAM \& RuBIN 1971). Furthermore, in a similar dose, it has been shown to decrease significantly left ventricular end-diastolic pressure, tension-time index and myocardial oxygen consumption in patients with normal and diseased coronary arteries (CoTE et al. 1974). In yet another study (IKRAM et al. 1973), diazepam (0.1 mg/kg i.v.) was shown to increase myocardial blood flow significantly in patients with both normal and diseased coronary arteries (the increase being more pronounced in the latter group). At higher dose levels $(0.7-0.8 \mathrm{mg} / \mathrm{kg}$ i.v. $)$, however, diazepam has been shown to increase heart rate, and to decrease significantly systolic and diastolic pressures, cardiac output, stroke volume and left ventricular stroke work, while total peripheral resistance did not change (RAo et al. 1973). Although hemodynamic changes following the diazepam dose $(0.15 \mathrm{mg} / \mathrm{kg}$ orally plus $0.3 \mathrm{mg} / \mathrm{kg}$ i.v. 1 h later) proposed for the present study have not been reported to our knowledge, they may be expected to be between the range of changes cited above.

This study was undertaken, therefore, to investigate whether ketamine in combination with diazepam, in the proposed doses, could be used for induction of anesthesia in cardiac surgical patients without causing excessive central sympathetic and cardiovascular stimulation, as reflected by changes in heart rate and arterial blood pressures and in plasma free norepinephrine (NE) and epinephrine $(\mathrm{E})$ concentrations.

\section{MATERIALS AND METHODS}

Twelve patients who were scheduled for clective openheart surgery for valvular replacement (eight) and direct aorto-coronary saphenous vein bypass graft operations (four) were studied. Their physical characteristics are shown in Table 1 . They had not received propranolol for 2 weeks prior to surgery. Their mean age was 53 years (range 29-65 years), mean weight $67 \mathrm{~kg}$ (range 40-95 kg) and mean height $166 \mathrm{~cm}$ (range $150-182 \mathrm{~cm})$. All patients had an ASA physical status classification of 3 or 4 .

Preanesthetic medication consisted of $0.15 \mathrm{mg} / \mathrm{kg}$ diazepam orally and $0.15 \mathrm{mg} / \mathrm{kg}$ morphine sulphate i.m., given $1 \mathrm{~h}$ before the patient was brought to the operating room. Atropine was not used in the premedication and/or prior to completion of the study. There was a period of 5 to $10 \mathrm{~min}$ between the insertion of intravenous and arterial catheters and the first baseline arterial blood sampling. No skin preparation, positional changes or instrumentation, other than the preceding (e.g. bladder catheterization, CVP catheter insertion), were allowed before and/or during the study.

Anesthesia was induced with $0.3 \mathrm{mg} / \mathrm{kg}$ diazepam given into a peripheral intravenous line during a 2 -minute period, while the patient breathed $100 \%$ oxygen. Ten minutes after diazepam, $2 \mathrm{mg} / \mathrm{kg}$ ketamine hydrochloride was given into a peripheral intravenous line over a 1-minute period. Ventilation was assisted as required throughout the study in order to maintain arterial $\mathrm{PCO}_{2}$ between 35 and $45 \mathrm{mmHg}$ (4.6 and 6.0 kPa). Arterial blood samples for blood-gas analysis and determination of plasma free norepinephrine and epinephrine concen trations were drawn prior to induction, 10 min after completion of the diazepam injection and $5 \mathrm{~min}$ after completion of ketamine administration.

A Radiometer (Copenhagen) blood gas analyzer 
Table 1

Physical characteristics of the patients.

\begin{tabular}{|c|c|c|c|c|c|}
\hline Number & $\begin{array}{c}\text { Age } \\
\text { (years) }\end{array}$ & Sex & $\begin{array}{l}\text { Height } \\
(\mathrm{cm})\end{array}$ & $\begin{array}{c}\text { Weight } \\
\text { (kg) }\end{array}$ & Primary diagnosis* \\
\hline 1 & 55.0 & $\mathrm{~F}$ & 165.0 & 62.0 & AS \\
\hline 2 & 60.0 & $\mathrm{~F}$ & 150.0 & 46.0 & $\mathrm{AS}, \mathrm{AI}, \mathrm{MS}, \mathrm{MI}$ \\
\hline 3 & 55.0 & $\mathbf{M}$ & 170.0 & 58.0 & MI, TI \\
\hline 4 & 29.0 & $\mathrm{~F}$ & I 55.0 & 50.0 & MS, TI \\
\hline 5 & 42.0 & $\mathbf{M}$ & 170.0 & 77.0 & CAD, Angina pectoris \\
\hline 6 & 53.0 & M & 177.0 & 95.0 & CAD, Angina pectoris \\
\hline 7 & 54.0 & $\mathbf{M}$ & 182.0 & 95.0 & CAD, Angina pectoris \\
\hline 8 & 52.0 & $\mathrm{~F}$ & 172.0 & 60.0 & MI \\
\hline 9 & 63.0 & $\mathrm{~F}$ & 157.0 & 40.0 & AI \\
\hline 10 & 58.0 & $\mathbf{M}$ & 162.0 & 82.0 & CAD, Angina pectoris \\
\hline 11 & 45.0 & M & 165.0 & 82.0 & AS \\
\hline 12 & 65.0 & $\mathbf{M}$ & 165.0 & 55.0 & MI \\
\hline $\begin{array}{c}\mathrm{N}=12 \\
\text { Mean }\end{array}$ & 53.0 & $\begin{aligned} \mathbf{M} & =7 \\
\mathbf{F} & =5\end{aligned}$ & 166.0 & 67.0 & \\
\hline
\end{tabular}

* AS = Aortic stenosis; AI = Aortic incompetence; $\mathrm{MS}=$ Mitral stenosis; $\mathrm{MI}=$ Mitral incompetence; $\mathrm{TI}=$ Tricuspid incompetence; $\mathrm{CAD}=$ Coronary artery disease.

was used for arterial blood-gas analysis; the plasma free norepinephrine and epinephrine concentrations were determined in duplicate by VenDSALu's method (1960), as modified by KeLsch et al. (1971). Laboratory personnel were not aware of the time of sampling, the sequence of samples or the nature of the study.

Arterial blood pressure was recorded on a Hewlett Packard multichannel recorder, via a Hewlett Packard strain gauge connected to an indwelling catheter in the radial artery. ECG lead II, or the lead giving the tallest R-wave, was continuously recorded and utilized in the calculation of heart rate at the time of sampling.

Student's $t$-test for paired data was used for statistical analysis; a $P$-value of $<0.05$ was considered to be statistically significant. The values in the text are means \pm s.e. mean, unless otherwise indicated.

\section{RESULTS}

\section{(1) Plasma free norepinephrine and epinephrine}

No significant increase in mean plasma free norepinephrine concentration was observed following diazepam and after ketamine, as compared to baseline in the 12 patients (Table 2). However, mean plasma free epinephrine concentration decreased significantly following ketamine (as seen in Table 2).

\section{(2) Heart rate}

No significant change in mean heart rates was observed following diazepam and after ketamine, as compared to baseline (Table 3 ).

\section{(3) Direct arterial pressures}

Mean systolic pressure readings did not show any significant change from baseline values following diazepam and after ketamine. Mean diastolic pressure did not change significantly following diazepam, but was elevated $5 \mathrm{~min}$ after ketamine $(P<0.05)$, as seen in Table 3 . The increase in mean diastolic pressure following ketamine was $12 \%$ over the baseline value.

Patient \#6 received sodium nitroprusside by intravenous infusion after the ketamine injection, while patient \#10 received a sodium nitroprusside infusion which was started even before diazepam administration, since systolic blood pressure exceeding 180 $\mathrm{mmHg}(23.9 \mathrm{kPa})$ in these patients was considered unacceptable by the cardiac surgicalanesthesia team. Both these patients were scheduled to undergo aorto-coronary bypass 
Table 2

Plasma free norepinephrine and epinephrine concentrations following diazepam-ketamine induction in cardiac surgical patients.

\begin{tabular}{|c|c|c|c|c|c|c|}
\hline \multirow[b]{2}{*}{ Number } & \multicolumn{3}{|c|}{ Norepinephrine conc. $\mathrm{ng} / \mathrm{ml}$} & \multicolumn{3}{|c|}{ Epinephrine conc. $\mathrm{ng} / \mathrm{ml}$} \\
\hline & Baseline & $\begin{array}{l}10 \text { min after } \\
\text { diazepam }\end{array}$ & $\begin{array}{l}5 \text { min after } \\
\text { ketamine }\end{array}$ & Baseline & $\begin{array}{l}10 \text { min after } \\
\text { diazepam }\end{array}$ & $\begin{array}{l}5 \text { min after } \\
\text { ketamine }\end{array}$ \\
\hline 1 & 0.30 & 0.35 & 036 & 0.15 & 0.20 & 0.00 \\
\hline 2 & 0.50 & 0.47 & 0.48 & 0.20 & 0.10 & 0.05 \\
\hline 3 & 0.47 & 0.48 & 0.85 & 0.00 & 0.00 & 0.00 \\
\hline 4 & 0.30 & 0.35 & 0.38 & 0.00 & 0.00 & 0.00 \\
\hline 5 & 0.33 & 0.34 & 0.31 & 0.00 & 0.00 & 0.00 \\
\hline $6^{*}$ & 0.35 & 0.40 & 0.38 & 0.50 & 0.24 & 0.02 \\
\hline 7 & 0.26 & 0.33 & 0.30 & 0.05 & 0.00 & 0.00 \\
\hline 8 & 0.40 & 0.27 & 0.30 & 0.11 & 0.00 & 0.00 \\
\hline 9 & 0.51 & 0.53 & 0.62 & 0.23 & 0.20 & 0.00 \\
\hline $10 \dagger$ & 0.64 & 0.63 & 0.42 & 0.00 & 0.00 & 0.00 \\
\hline 11 & 0.40 & 0.30 & 0.34 & 0.00 & 0.00 & 0.00 \\
\hline 12 & 0.26 & 0.27 & 0.31 & 0.00 & 0.00 & 0.00 \\
\hline Mean & 0.39 & 0.39 & 0.42 & 0.10 & 0.06 & 0.006 \\
\hline \pm s.e. mean & 0.03 & 0.03 & 0.05 & 0.04 & 0.03 & 0.003 \\
\hline$P$-value & & & $\Sigma 0.5$ & & $>0.05$ & $<0.05$ \\
\hline
\end{tabular}

* Patient received intravenous $\mathrm{Na}$ nitroprusside infusion soon after ketamine administration. $\uparrow$ Patient received intravenous $\mathrm{Na}$ nitroprusside infusion throughout the study.

operations. An exception was made in patient \#9 who had chronic hypertensive cardiovascular disease, and whose systolic pressure was $200 \mathrm{mmHg}(26.6 \mathrm{kPa})$ throughout the study. She did not receive sodium nitroprusside because her resting preoperative systolic pressure was between 180 and 200 $\mathrm{mmHg}$ (23.9 and $26.6 \mathrm{kPa}$ ).

\section{(4) Arterial Blood Gases}

Arterial $\mathrm{P}_{\mathrm{O}_{2}}$ was maintained at over 290 $\mathrm{mmHg}$ in all patients during the study. Mean arterial $\mathrm{P}_{\mathrm{CO}_{2}}$ was $38.5 \pm 1.25 \mathrm{mmHg}$ (5.12 $0.17 \mathrm{kPa})$ prior to induction, $37.5 \pm 1.61$ $\mathrm{mmHg} \quad(4.99 \pm 0.21 \mathrm{kPa}) 10 \mathrm{~min}$ after diazepam and $37.5 \pm 2.17 \mathrm{mmHg}(4.99 \pm 0.29$ $\mathrm{kPa} 5 \mathrm{~min}$ after ketamine administration.

\section{(5) $E C G$}

No arrhythmias or ST, T-wave changes were noted in any of the patients during the study period.

\section{(6) Complications}

There was no evidence of any allergic reaction or other complications during the study period in any of the patients.

\section{DISCUSSION}

The absence of significant increases in heart rate and systolic arterial blood pressure, and a statistically significant though modest $(12 \%)$ increase in diastolic pressure indicate that no marked increase in sympathetic tone was induced following the diazepam and ketamine induction sequence in this group of cardiac surgical patients. This is further confirmed by a lack of significant increase in plasma free norepinephrine concentration following diazepam and ketamine and by a significant decrease in plasma iree epinephrine concentration following ketamine administration. Giving ketamine alone to a series of control cardiac surgical patients was con- 


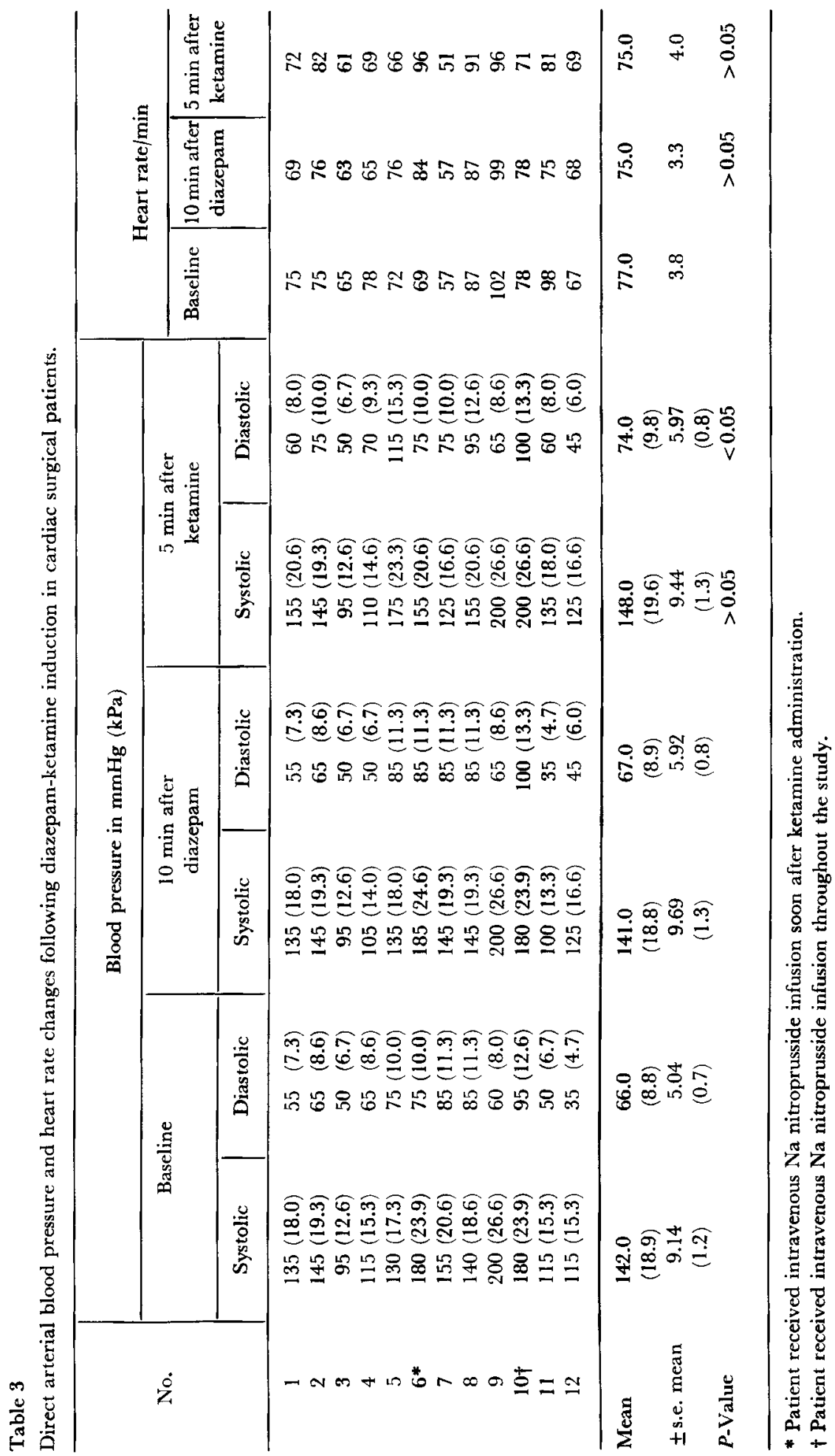


sidered to be too hazardous and consequently ethically unacceptable, and was therefore not done. However, in an earlier study (ZsIGMOND et al. $1974 \mathrm{a}$ ) in 12 patients without cardiac disease who were given ketamine $2 \mathrm{mg} / \mathrm{kg}$ intravenously, plasma free norepinephrine increased from a baseline value of $0.4 \pm 0.04$ $\mathrm{ng} / \mathrm{ml}$ to $0.8 \pm 0.10 \mathrm{ng} / \mathrm{ml}(P<0.001)$; there was no significant change in plasma free epinephrine, which was undetectable in baseline samples and could be measured in only two patients $5 \mathrm{~min}$ after its administration. In these same 12 patients, heart rate and systolic arterial pressure were $70.6 \pm 7.4$ beats $/ \mathrm{min}$ and $120.5 \pm 6.5 \mathrm{mmHg}(16.0 \pm 0.86 \mathrm{kPa})$, respectively, before and $95.3 \pm 10.1$ beats $/ \mathrm{min}$ $(P<0.05)$ and $146.5 \pm 7.8 \mathrm{mmHg}(19.48 \pm$ $1.04 \mathrm{kPa})(P<0.01) 5 \mathrm{~min}$ after ketamine administration but prior to intubation.

Arterial blood was selected for sampling for free norepinephrine and epinephrine levels because of the greater ease and rapidity of collection of large $(20 \mathrm{ml})$ samples, as compared to peripheral venous samples. This is essential because the half-life of norepinephrine in plasma in vivo is less than 2 min (Whitвy et al. 1961). Central venous catheterization prior to induction of anesthesia was considered too stressful. Since it has been shown that in anesthetized patients about $25 \%$ of infused ${ }^{3} \mathrm{H}$-norepinephrine is removed in a single passage through the lungs (GILLIS et al. 1972), arterial levels of free norepinephrine in the present study are likely to be lower than they would have been in comparable central venous samples. However, in our earlier studies (Zsigmond et al. 1974b), arteriovenous differences of plasma free norepinephrine determined in the radial artery and the contralateral antecubital vein did not change significantly following ketamine administration in patients. Although the baseline arterial plasma free norepinephrine level of $0.39 \pm 0.03 \mathrm{ng} / \mathrm{ml}$ in the present study group is significantly higher $(P<0.01)$ than the resting plasma free norepinephrine level of $0.32 \pm 0.01 \mathrm{ng} / \mathrm{ml}$ in the arterial blood of 34 noncardiac patients in the previous study (Zsigmond et al. 1974b), the difference can be explained, on the basis of a lower mean age ( 40 years) in the latter group, according to the equation described by LAKE et al. (1977).

Decreased arterial plasma free epinephrine levels following ketamine may be due to a reduction in adrenomedullary activity accompanying loss of consciousness and onset of anesthesia in the absence of sensory or chemical stimuli to the central nervous system. The clinical significance of this finding is doubtful, however, because in 6 out of the 12 patients in the study, plasma free epinephrine was undetectable throughout the study period. Similar inconsistency in plasma epinephrine levels has been reported following thiopental, cyclopropane, halothane and diethylether, and it has been suggested that adrenal medullae do not participate to any large extent in the sympathetic nervous response to anesthesia in man (PRICE et al. 1959).

The increase in diastolic pressure caused by ketamine may be due to a moderate increase in the central sympathetic activity not manifested by an overflow in NE from receptor sites. However, it may also be due to a direct peripheral effect of ketamine on post-ganglionic adrenergic neurons, where it has been shown to decrease the re-uptake of $\mathrm{NE}$ in rats (Miletich et al. 1973), which in turn may cause peripheral vasoconstriction.

Although the mean plasma free NE concentration and mean systolic blood pressure for the whole group did not change significantly following diazepam or ketamine administration, this pattern was not consistently seen in individual patients. Thus no statistically significant correlation was found between systolic blood pressure and $\mathrm{NE}$ (correlation coefficient $(\mathrm{CC})=-0.15$ ) or $\mathrm{E}(\mathrm{GG}=0.08)$, and between diastolic blood pressure and $\mathrm{NE}(\mathrm{CG}=-0.37)$ or $\mathrm{E}$ $(\mathrm{CC}=0.02)$ values as observed $5 \mathrm{~min}$ after ketamine administration. Similarly there was no statistically significant correlation between changes in systolic blood pressure $5 \mathrm{~min}$ after ketamine administration as compared to bascline and similar changes in $\mathrm{NE} \quad(\mathrm{CC}:=$ 
$-0.35)$ or $\mathrm{E}(\mathrm{CC}=0.47)$ concentrations, nor in changes in diastolic blood pressure 5 min after ketamine administration as compared to baseline and similar changes in NE $(\mathrm{CG}=-0.26)$ and $\mathrm{E}(\mathrm{CG}=0.25)$ concentrations.

The lack of correlation between blood pressure and plasma free norepinephrine and epinephrine suggests that factors other than changes in sympathetic tone, as reflected by changes in plasma free norepinephrine and epinephrine, may be more important in determining the blood pressure at a given moment. Thus it has been suggested that vasomotor reactivity in patients with coronary artery disease is increased (HANson et al. 1976); therefore a given vasomotor stimulus may evoke an exaggerated hypertensive response in these patients and also the response may last for a longer time. A similar vascular hyperreactivity has also been suggested in patients with chronic essential hypertension (Doyle \& Fraser 1961). Also when adjusted for age, resting plasma free norepinephrine levels in patients with chronic essential hypertension have been shown to be comparable to a group of normotensive subjects (LAKE et al. 1977). Therefore the resting plasma NE concentrations may not necessarily be related to the resting blood pressure.

However, it is also possible that changes in plasma free norepinephrine and epinephrine concentrations may not accurately represent corresponding changes in sympathetic tone, since they are governed by several other factors, including reuptake by adrenergic nerve endings, tissue uptake and metabolism. Within the context of the present study, however, measurements of plasma free norepinephrine and epinephrine do show that pretreatment with diazepam in the described dose can effectively prevent a rise in plasma free norepinephrine following ketamine administration. This indicates that a marked sympathetic stimulation does not occur when this combination of drugs is used for induction of anesthesia.

One of the major objections to the use of ketamine for induction of anesthesia in cardiac surgical patients has been its tendency to increase central sympathetic activity, leading to marked cardiovascular stimulation. Addition of an adequate dose of diazepam prior to its administration can therefore reduce this stimulation sufficiently to make this combination quite useful in this group of patients.

Another major objection to the use of ketamine in adults has been a high incidence of psychic side effects following its use (Corssen et al. 1968). Diazepam in the doses used in the present study has been shown to reduce significantly $(P \leq 0.001)$ the incidence of these reactions, at least in patients free of cardiovascular disease (Kothary \& ZsigMOND 1976). Some of the other advantages of this combination of drugs are a lack of hypotension, cardiac arrhythmias and histamine release.

The number of patients in this group is not large enough for valid statistical comparisons of the data for the patients with valvular disease vs. the group with coronary artery disease. However, the data presented here would suggest that a combination of diazepam and ketamine, when given according to the specified protocol, can induce anesthesia safely in patients undergoing cardiac valvular replacement or coronary artery bypass operations. Further investigation in a larger patient population, particularly with regard to changes in various hemodynamic parameters during this induction sequence, is needed before this technique can be recommended for widespread clinical use.

In conclusion, therefore, the combination of diazepam and ketamine, when used for induction of anesthesia in cardiac surgical patients according to the specified protocol, does not result in clinically significant central sympathetic stimulation or excessive cardiovascular stimulation.

\section{REFERENCES}

Cihasapakis, G., Kekis, N., Sakkalis, C. \& Kolios, D. (1973) Use of ketamine and pancuronium for anes- 
thesia for patients in hemorrhagic shock. Anesth. Analg. 52, 282.

Corssen, G., Mryasaka, M. \& Domno, E. F. (1968) Changing concepts in pain control during surgery: dissociative anesthesia - a progress report. Anesth. Analg. 47, 746.

Cionssen, G., Allarde, R., Brosch, F. \& Arbenz, G. (1970) Ketamine as the sole anesthetic in open-heart surgery: a preliminary report. Anesth. Analg. 49, 1025.

Cote, P., Gueret, T. \& Bourassa, M. G. (1974) Systemic and coronary hemodynamic effects of diazepam in patients with normal and diseased coronary arteries. Circulation 50, 1210.

Dalen, J. E., Evans, G. L., Banas, J. S., Jr., Brooks, H. L., Paraskos, J.A. \& Dexter, L. (1969) The hemodynamic and respiratory effects of diazepam (Valium). Anesthesiology 30, 259.

Doyle, S. E. \& Fraser, J. R. E. (1961) Essential hypertension and inheritance of vascular hyperreactivity. Lancet ii, 509.

Dundee, J. W., Bovill, J. G., Clarke, R. S. J. \& Pandit, S. K. (1971) Problems with ketamine in adults. Anaesthesia 26, 86 .

Gillis, C. N., Green, N. M., Gronau, L. H. \& Hammond, G. L. (1972) Pulmonary extraction of 5-hydroxytryptamine and norepinephrine before and after cardiopulmonary bypass in man. Circ. Res. 30, 666.

Hanson, E. L., Kane, P. B., Askanazi, J., Neville, J. F., JR. \& WEBB, W. R. (1976) Comparison of patients with coronary artery or valve disease: intraoperative differences in blood volume and observations of vasomotor response. Ann. Thorac. Surg. 22, 343.

Ikram, H. \& Rubin, A. P. (1971) Anaesthesia for cardioversion. Brit. med. 7. 4, 626.

Ikram, H., Rubin, A. P. \& Jewkes, R. F. (1973) Effect of diazepam on myocardial blood flow of patients with and without coronary artery disease. Brit. Heart 7. 35, 626.

Ivankovich, A. D., Miletich, D. J., Reimann, Ci., Albrechr, R. F. \& ZAHED, B. (1974) Cardiovascular effects of centrally administered ketamine in goats. Anesth. Analg. 53, 924.

Kelsch, R. C., Light, G. S., Luciano, J. R. \& Oliver, W. J. (1971) The effects of prednisone on plasma norepinephrine concentration and renin activity in salt depleted men. F. Lab. clin. Med. 77, 267.

Kothary, S. P. \& Zsigmond, E. K. (1976) A doubleblind study of the effective antihallucinatory doses of diazepam prior to ketamine anesthesia. Clin. Pharmacol. Ther. 21, 108.

Lake, C. R., Ziegler, M. G., Coleman, M. D. \& KopIn, I. J. (1977) Age-adjusted plasma norepiphrine levels are similar in normotensive and hypertensive subjects. New Engl, 7. Med. 296, 208.

Miletich, D. J., Ivankovich, A. D., Albrecht, R. F.,
Zahed, B. \& I lail A. A. (1973) The elfect of ketamine on catecholamine metabolism in the isolated perfused rat heart. Anesthesiology 39, 271.

Price, H. L., Linde, H. W., Jones, R. E., Black, G. W. \& PrICE, M. L. (1959) Sympathoadrenal responses to general anesthesia in man and their relation to hemodynamics. Anesthesiology 20, 563.

Rao, S., Sherleaniuk, R. W., Prasad, K., Lee, S. J. K. \& Sproule B. J. (1973) Cardiopulmonary effects of diazepam. Clin. Pharmacol. Ther. 14, 182

Stanley, T. H. (1973) Blood pressure and heart-rate responses to ketamine during general anesthesia. Anesthesiology 39, 648.

Traber, D. L.., Wilson, R. D. \& Priano, L. L. (1968) Differentiation of the cardiovascular effects of CI-581. Anesth. Analg. 47, 769.

TRABER, D. L. \& Wilson, R. D. (1969) Involvement of the sympathetic nervous system in the pressor response to ketamine. Anesth. Analg. 48, 248.

Traber, D. L., Wilson, R. D. \& Priano, L. L. (1970a) Blockade of the hypertensive response to ketamine. Anesth. Analg. 49, 420.

Traber, D. L., Wilson, R. D. \& Priano, L. L. (1970b) A detailed study of the cardiopulmonary response to ketamine and its blockade by atropine. South. Med. 7. 63, 1077.

Traber, D. L., Wilson, R. D. \& Priano, L. L. (1971) The effect of alpha-adrenergic blockade on the cardiopulmonary response to ketamine. Allesth. Analg. 50, 737.

Tweed, W. A., Minuck, M. \& Mymin, D. (1972) Circulatory responses to ketamine anesthesia. Anesthesiology 37, 613.

Vendsalu, A. (1960) Studies on adrenalin and noradrenalin in human plasma. Acta physiol. scand. 48, Suppl. 173.

Virtue, R. W., Alanis, J. M., Mori, M., La Fargut, R. T., Vogel, J. H. K. \& Metcalf, D. R. (1967) An anesthetic agent: 2 orthochlorophenyl, 2 methylamino cyclohexanone $\mathrm{HCl}$ (CI-581). Anesthesiology 28,823 .

Whitby, L. G., Axelrod, J. \& Weil-Malherb, H. (1961) The fate of ${ }^{3} \mathrm{H}$-norepinephrine in animals. 7 . Pharmacol. exp. Ther. 132, 191.

Zsigmond, E. K., Kelsch, R. C., Kothary, S. P. \& VADNAY, L. (1974a) Rise in plasma free norepinephrine during anesthetic induction with ketaminc. Physician's Drug Manual 5-6, 81.

Zsigmond, E. K., Kothary, S. P., Matsuri, A. \& Martinez, O. (1974b) Atara-analgesia mixtures: diazepam-ketamine. Excerpta Medica: International Congress Series No. 347, 136.

\section{Address :}

Surendra M. Kumar, M.D.

Department of Anesthesiology

University of Michigan Medical Center

Ann Arbor, Michigan 48109, U.S.A. 